\section{(6) OPEN ACCESS}

For numbered affiliations see end of article.

\section{Correspondence to} Dr Tien Y Wong, Singapore Eye Research Institute, Singapore National Eye Centre, National University of Singapore, 11 Third Hospital Avenue, Singapore 168751, Singapore; ophwty@nus.edu.sg

Received 7 March 2014 Revised 7 May 2014 Accepted 3 June 2014 Published Online First 2 July 2014

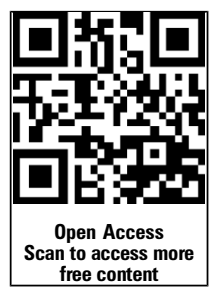

\title{
Myopic choroidal neovascularisation: current concepts and update on clinical management
}

\author{
Tien Y Wong, ${ }^{1}$ Kyoko Ohno-Matsui, ${ }^{2}$ Nicolas Leveziel, ${ }^{3}$ Frank G Holz, ${ }^{4}$ Timothy Y Lai, ${ }^{5}$ \\ Hyeong Gon Yu, ${ }^{6}$ Paolo Lanzetta, ${ }^{7}$ Youxin Chen, ${ }^{8}$ Adnan Tufail ${ }^{9}$
}

\begin{abstract}
Choroidal neovascularisation (CNV) is a common visionthreatening complication of myopia and pathological myopia. Despite significant advances in understanding the epidemiology, pathogenesis and natural history of myopic CNV, there is no standard definition of myopic CNV and its relationship to axial length and other myopic degenerative changes. Several treatments are available to ophthalmologists, but with the advent of new therapies there is a need for further consensus and clinical management recommendations. Verteporfin photodynamic therapy has been an established treatment for subfoveal myopic CNV for many years, but this treatment does not restore visual acuity and is associated with long-term chorioretinal atrophy. More recently, clinical trials investigating the efficacy and safety of anti-vascular endothelial growth factor agents in patients with myopic CNV have demonstrated substantial visual acuity gains and quality of life increases compared with photodynamic therapy. These enhanced outcomes provide updated evidence-based clinical management guidelines of myopic CNV, and increase the need for a generally accepted definition for myopic CNV. This review critically summarises the latest myopic CNV literature in the context of clinical experience and recommends a myopic CNV treatment algorithm.
\end{abstract}

\section{INTRODUCTION}

Myopic choroidal neovascularisation $(\mathrm{CNV})$ is a common vision-threatening complication of myopia and pathological myopia (PM). ${ }^{1-4}$ The clinical definition and terminology surrounding myopic $\mathrm{CNV}$ varies, with myopic $\mathrm{CNV}$ also commonly being referred to as subretinal neovascularisation in PM, Fuchs' spot or Forster-Fuchs' retinal spot in $\mathrm{PM}$, and disciform degeneration in PM. While myopic CNV is historically thought to only occur in eyes with PM, it is now recognised that myopic $\mathrm{CNV}$ can occur at any degree of myopia and in eyes without typical myopic degenerative fundus changes. ${ }^{5}$ Therefore, in clinical practice, $\mathrm{CNV}$ can be attributed to be 'myopic' in aetiology by the refractive status of the eye and the exclusion of other disorders associated with CNV.

There are now effective therapeutic options for myopic CNV, in particular anti-vascular endothelial growth factor (VEGF) therapy. This review summarises current concepts in pathogenesis, epidemiology, natural history, and management options for myopic CNV.

\section{PATHOGENESIS OF MYOPIC CNV}

Several theories have been proposed to explain the development of myopic CNV, reviewed in detail elsewhere. ${ }^{4}$ The mechanical theory is based on the assumption that the progressive and excessive elongation of the anteroposterior axis causes a mechanical stress on the retina, leading to an imbalance between pro-angiogenic and anti-angiogenic factors, resulting in myopic $\mathrm{CNV}^{7}$ In support, the presence of lacquer cracks has been shown to be a predisposing factor for the development of myopic $\mathrm{CNV}^{8}{ }^{9}$

The heredodegenerative theory states that myopic refractive errors are genetically predetermined. ${ }^{4}{ }^{10}$ In support, studies have shown that single nucleotide polymorphisms in several genes (eg, pigment epithelium-derived factor) are associated with the development and progression of myopic CNV. 1112

The haemodynamic theory for the development of myopic CNV relates to perfusion changes in the choroidal circulation of the myopic eye, such as choroidal filling delay and diffuse thinning of the choroid. $^{4}{ }^{13}$ However, evidence has shown that myopic CNV can develop in eyes with shallow staphyloma and preserved choroidal circulation, suggesting that haemodynamic factors may not have a strong role in the development of myopic $\mathrm{CNV}^{14}$

\section{DIAGNOSIS OF MYOPIC CNV}

Myopic CNV is typically seen as a small, flat, greyish membrane on slit-lamp biomicroscopy that may have a hyper-pigmented border if chronic or recurrent. ${ }^{1-4}$ Symptoms of myopic CNV include a decrease in vision, central scotoma and/or metamorphopsia. ${ }^{15} 16$

The standard tests for diagnosing myopic CNV are fundus biomicroscopy, fluorescein angiography (FA) and optical coherence tomography (OCT). FA and OCT are generally recommended baseline diagnostic tests for myopic CNV in conjunction with colour photos and clinical examination. FA demonstrates the presence, type, area and activity of myopic CNV, and helps exclude other disorders. ${ }^{4} 17$ The majority of myopic CNV presents as a 'classic' pattern on $\mathrm{FA},{ }^{18}$ with well defined hyperfluorescence in the early phases and leakage of fluorescein dye during the late phases. ${ }^{4} 1517$ OCT is usually mandatory for the identification of the fovea, assessment of retinal thickness and presence of extracellular fluid, and for establishing a baseline to judge future treatment response. ${ }^{15}$ On OCT, myopic CNV presents as a highly reflective area contiguous above the retinal pigment epithelium (sometimes referred to as 'type $2 \mathrm{CNV}$ ') with 
Table 1 Coexisting pathologies and differential diagnosis for myopic CNV

\begin{tabular}{|c|c|}
\hline $\begin{array}{l}\text { Other co-existing degenerative } \\
\text { changes associated with myopia }\end{array}$ & Differential diagnosis for CNV \\
\hline Myopic traction maculopathy (foveoschisis) & Neovascular AMD \\
\hline Macular hole & $\begin{array}{l}\text { Myopic macular haemorrhage due } \\
\text { to lacquer cracks }\end{array}$ \\
\hline Retinal tear/detachment & $\begin{array}{l}\text { Punctate inner choroidopathy } \\
\text { (usually coexists with myopia) }\end{array}$ \\
\hline Dome-shaped macula & Multifocal choroiditis \\
\hline Staphyloma & Idiopathic CNV* \\
\hline $\begin{array}{l}\text { Atrophic changes (patchy atrophy, } \\
\text { tesselated changes and diffuse atrophy) }\end{array}$ & \\
\hline
\end{tabular}

minimal subretinal fluid. ${ }^{4}$ Fundus autofluorescence, which allows the visualisation of accumulated lipofuscin within the retinal pigment epithelium, may be included as part of any basic diagnosis and follow-up examination, as it may aid in the assessment of myopic CNV progression (and associated geographic atrophy). ${ }^{4}$

There are several differential diagnoses and pathologies that must be excluded from myopic CNV when examining a patient with myopia and vision loss (table 1). Other complications of PM should be identified with OCT/FA, such as myopic traction maculopathy, epiretinal membrane, vitreomacular traction and myopic full-thickness or lamellar macular hole, as these require different treatments from myopic CNV. In particular, retinal haemorrhage due to new lacquer crack formation and macular exudative changes associated with a dome-shaped macula or a staphyloma should be identified and excluded on OCT/FA (figure 1). ${ }^{4}$ In case of significant haemorrhage, indocyanine green angiography (ICGA) can identify the presence of lacquer cracks and/or CNV. It should be noted that OCT alone cannot differentiate myopic CNV from subretinal bleeding due to new lacquer crack formation, which could lead to unnecessary treatment by anti-VEGF therapy for subretinal bleeding without CNV. In addition, myopic CNV should be differentiated from other causes of CNV (eg, multifocal choroiditis or punctate inner choroidopathy or age-related macular degeneration (AMD)). ${ }^{19-21}$ Importantly, myopic CNV has different lesion characteristics to AMD-CNV, especially in younger individuals, ${ }^{42}$ but is a predominantly 'classic', 'type 2' CNV; that is, smaller than that of AMD, with minimal subretinal fluid and an absence of drusen at the typical age of onset. ${ }^{4}$

\section{EPIDEMIOLOGY OF MYOPIC CNV}

A recent systematic review has indicated that the prevalence of $\mathrm{PM}$ is $1-3 \%$ in adults, and that $5-11 \%$ of patients with PM
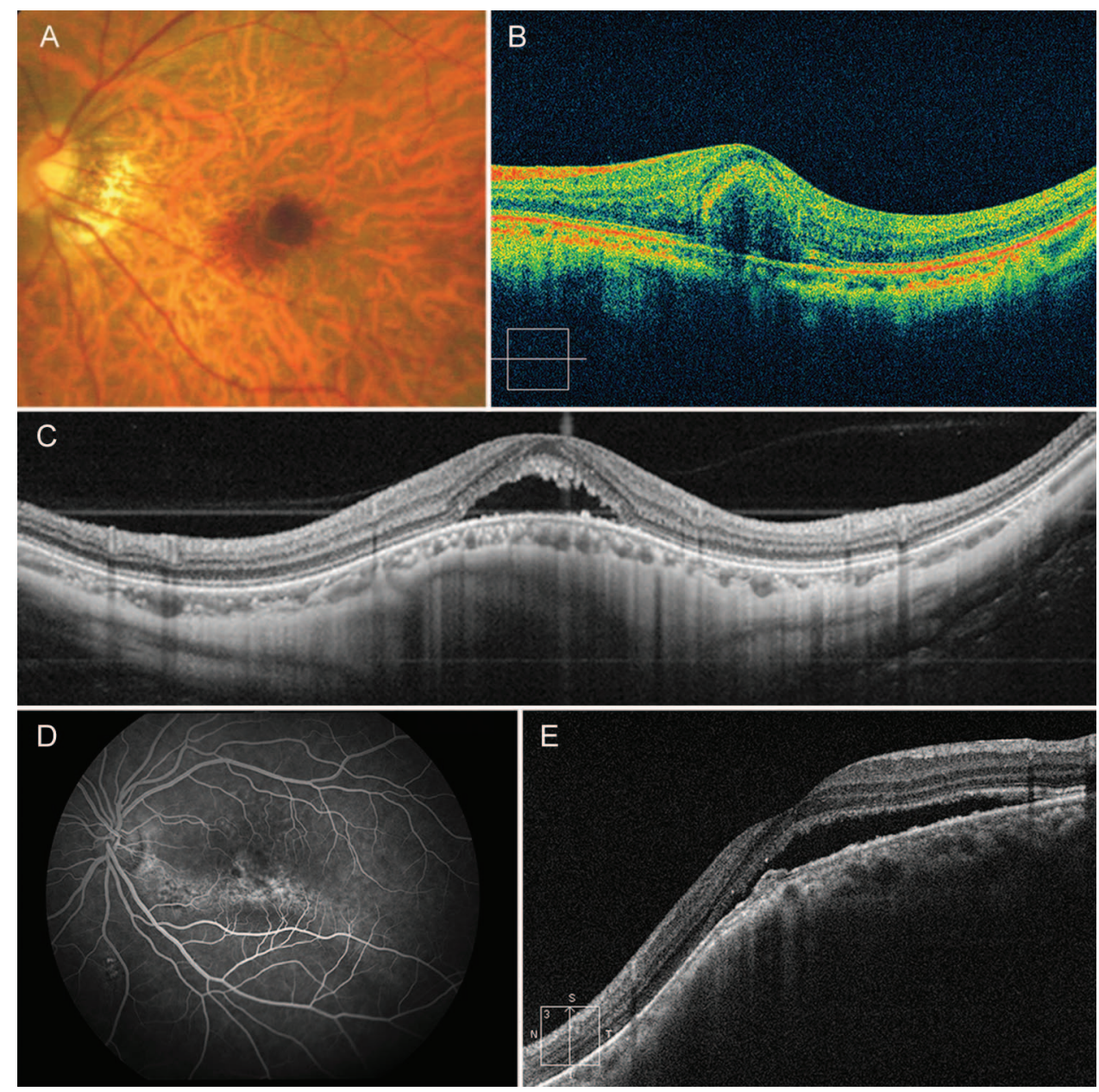

Figure 1 Differential diagnosis for myopic choroidal neovascularisation (CNV): (A and B) haemorrhage due to lacquer cracks; (C) dome-shaped macula with serous retinal detachment; and ( $D$ and $E$ ) macular fluid due to staphyloma. 
develop $\mathrm{CNV}^{23}$ While these data provide some insight into the epidemiology of myopic CNV, the results should be interpreted with caution, since the definitions of myopia, PM and myopic $\mathrm{CNV}$ between studies were not uniform. ${ }^{23}$ Furthermore, the data were based on only a few published studies, indicating the need for further incidence and prevalence studies in different populations.

\section{NATURAL HISTORY OF MYOPIC CNV}

Several of the phenotypic features of PM are associated with increased risk of myopic $\mathrm{CNV}$ - these include lacquer cracks, ${ }^{8}$ patchy atrophy, ${ }^{8}$ thinning of the choriocapillaris and choroid, ${ }^{13}$ and $\mathrm{CNV}$ in the fellow eye. ${ }^{6}$ In a retrospective study of 73 patients with PM, 17 (23\%) presented with bilateral myopic $\mathrm{CNV}^{24}$ Furthermore, one study has shown that after initial presentation of myopic CNV, CNV develops in the fellow eye in
$35 \%$ of patients within 8 years. ${ }^{8}$ There appears to be three main stages of myopic CNV, all of which are associated with vision loss (figure 2). ${ }^{4}$ The initial phase results in direct damage to photoreceptors, causing central visual loss. ${ }^{3} 2526$ Then, as the $\mathrm{CNV}$ regresses, ${ }^{26}$ a fibrous pigmented scar forms, sometimes referred to as Fuchs' spot or Forster-Fuchs' retinal spot. Finally, atrophy forms around the regressed $\mathrm{CNV}$, which is a major late complication of myopic CNV and a key contributor to the poor long-term visual outcomes associated with the condition. ${ }^{4} 2526$ It is important to note that $\mathrm{CNV}$ can occur in eyes with no other evident degenerative changes or isolated tesselated fundus. ${ }^{1} 2728$

Factors generally associated with poor visual prognosis include subfoveal (rather than juxtafoveal or extrafoveal) location (determined via OCT) ${ }^{329}$ age $>40$ years, ${ }^{27}{ }^{28}$ size of the CNV lesion $(>400 \mu \mathrm{m})^{3}$ and lower baseline best-corrected visual acuity
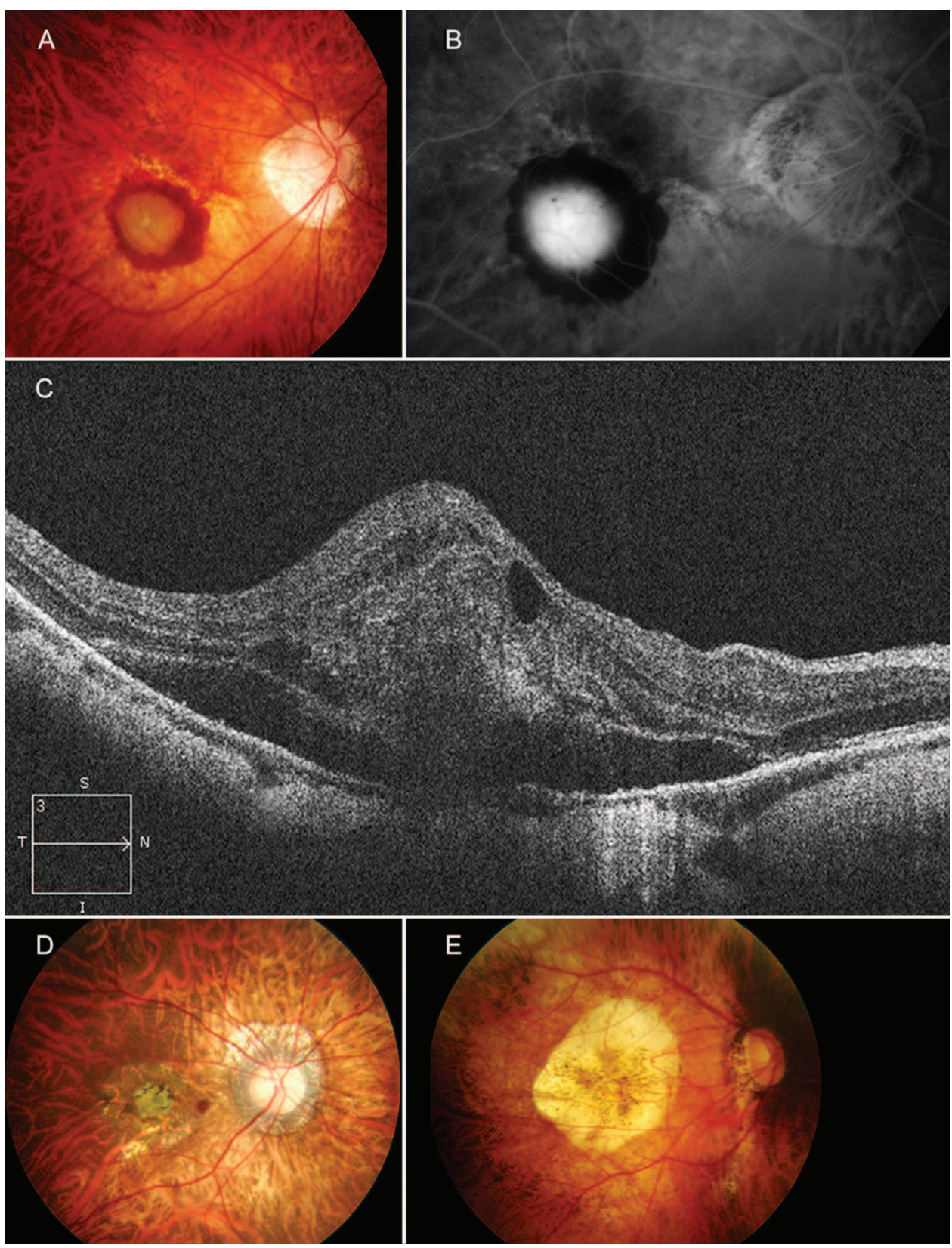

Figure 2 Active myopic choroidal neovascularisation (CNV) imaged via (A) colour fundus photography; (B) fluorescein angiography; and (C) optical coherence tomography. (D) A fibrous pigmented scar (Fuchs' spot). (E) Chorioretinal atrophy following regression of active myopic CNV. 
(BCVA). ${ }^{27} 29$ Long-term studies show almost all patients lose significant vision. ${ }^{326-31}$ In a 10 -year follow-up of 25 patients with myopic CNV, visual acuity was $<20 / 200$ in $89 \%$ and $96 \%$ of patients 5 and 10 years after onset of $\mathrm{CNV}$, respectively. ${ }^{26}$

\section{TREATMENT OPTIONS FOR MYOPIC CNV}

Before the introduction of intravitreal anti-VEGF therapy for CNV, laser photocoagulation, verteporfin photodynamic therapy (vPDT) and surgical excision or macular translocation were performed to treat CNV. These were recently reviewed elsewhere ${ }^{4}$; the most common treatments are summarised below.

\section{Laser photocoagulation}

Laser photocoagulation was used widely to treat extrafoveal myopic $\mathrm{CNV}^{32-34}$ although evidence supporting its use is limited. ${ }^{4}$ Laser causes retinal tissue damage with laser scar expansion or atrophy, does not maintain long-term visual acuity and is associated with a high rate of recurrence. ${ }^{3-35}$

\section{Verteporfin photodynamic therapy}

vPDT is an established, approved treatment for subfoveal myopic CNV. In the Verteporfin Photodynamic Therapy (VIP trial), while vPDT was well tolerated and more efficacious than placebo over 12 months of treatment, vPDT generally stabilised but did not improve visual acuity. ${ }^{18}$ These findings are supported by 12 short-term (<12 months) ${ }^{36-47}$ and 6 long-term ( $\geq 36$ months) ${ }^{404547-50}$ studies. However, a 2-year follow-up of the VIP trial showed no statistically significant benefit in visual outcome with vPDT compared with placebo, although the trial may be underpowered to detect differences. ${ }^{51}$

The most important limitation of vPDT is long-term chorioretinal atrophy which may develop in some patients, contributing to vision loss. ${ }^{40} 49$ However, since atrophy is a prominent feature of myopic CNV, further studies are required to determine whether this atrophy is accelerated by vPDT or is part of the disease's natural history. ${ }^{8}$

\section{Anti-VEGF therapy}

Ranibizumab

Currently, ranibizumab (Lucentis) is the only licensed anti-VEGF therapy for treatment of myopic CNV. Its use is supported by data from phase II (REPAIR) and phase III trials (RADIANCE). ${ }^{52-54}$ In addition, the 12-month efficacy and safety of ranibizumab for myopic CNV have been demonstrated in several small prospective and retrospective studies with lower levels of evidence ${ }^{55}$ (table 2). ${ }^{56-63}$ Further small studies have

Table 2 Mean change in BCVA after 12 months' treatment with anti-VEGF therapy

\begin{tabular}{|c|c|c|c|c|c|c|c|}
\hline Drug & Study & Design & $\begin{array}{l}\text { Total sample } \\
\text { size (patients) }\end{array}$ & $\begin{array}{l}\text { Patients receiving } \\
\text { anti-VEGF } \\
\text { treatment }\end{array}$ & $\begin{array}{l}\text { Mean change } \\
\text { in BCVA (ETDRS } \\
\text { letters) }\end{array}$ & $\begin{array}{l}\text { Injection number } \\
\text { over } 12 \text { months } \\
\text { (mean) }\end{array}$ & $\begin{array}{l}\text { OCEBM level } \\
\text { of evidence }\end{array}$ \\
\hline \multirow[t]{7}{*}{ Ranibizumab } & RADIANCE 52 & Phase III, randomised, double & 277 & $106^{*}$ & 13.8 & 4.6 & 2 \\
\hline & & $\begin{array}{l}\text { masked, active controlled, } \\
\text { multicentre }\end{array}$ & & $116 t$ & 14.4 & 3.5 & \\
\hline & REPAIR $^{53}$ & $\begin{array}{l}\text { Phase II, prospective, open } \\
\text { label, multicentre }\end{array}$ & 65 & 65 & 13.8 & 3.6 & 4 \\
\hline & $\begin{array}{l}\text { Franqueira et al } \\
2012^{57}\end{array}$ & Retrospective case series & 39 & 39 & 4.3 & 4.1 & 4 \\
\hline & $\begin{array}{l}\text { Monés et al } \\
2009^{59}\end{array}$ & Prospective case series & 23 & 23 & 9.5 & 1.5 & 4 \\
\hline & Silva et al $2010^{60}$ & $\begin{array}{l}\text { Prospective case series, } \\
\text { multicentre }\end{array}$ & 32 & 32 & 8 & 3.6 & 4 \\
\hline & Lai et al $2009^{62}$ & Retrospective case series & 16 & 16 & $15 \ddagger$ & 3.8 & 4 \\
\hline \multirow[t]{11}{*}{ Bevacizumab } & Ikuno et al $2009^{64}$ & Retrospective case series & 63 & 63 & $11.5 \ddagger$ & 2.4 & 4 \\
\hline & Chan et al $2009^{65}$ & Prospective case series & 29 & 29 & $12 \ddagger$ & 3.6 & 4 \\
\hline & $\begin{array}{l}\text { Gharbiya et al } \\
2009^{66}\end{array}$ & Prospective case series & 20 & 20 & 18.2 & 4.0 & 4 \\
\hline & Ruiz-Moreno et al & Prospective, comparative, & 38 & $18 \S$ & 6.3 & 3.2 & 4 \\
\hline & $2011^{67}$ & non-randomised multicentre & & 209 & 7.2 & 1.7 & \\
\hline & $\begin{array}{l}\text { Ruiz-Moreno et al } \\
2010^{68}\end{array}$ & $\begin{array}{l}\text { Retrospective case series, } \\
\text { multicentre }\end{array}$ & 107 & 107 & 8.7 & $1+\dagger$ & 4 \\
\hline & $\begin{array}{l}\text { Ruiz-Moreno et al } \\
2011,2013^{69} 70\end{array}$ & $\begin{array}{l}\text { Prospective, randomised, } \\
\text { multicentre }\end{array}$ & 55 & 25 & 11.2 & 3.5 & 3 \\
\hline & $\begin{array}{l}\text { lacono et al } \\
2011^{71}\end{array}$ & Prospective case series & 30 & 30 & 3.8 & 4.7 & 4 \\
\hline & $\begin{array}{l}\text { Gharbiya et al } \\
2012^{72}\end{array}$ & Prospective case series & 30 & 30 & 16.4 & 4.1 & 4 \\
\hline & $\begin{array}{l}\text { Hayashi et al } \\
2012^{73}\end{array}$ & Prospective case series & 69 & 69 & $10.5 \ddagger$ & $N R \ddagger \ddagger$ & 4 \\
\hline & $\begin{array}{l}\text { Hayashi et al } \\
2009^{74}\end{array}$ & Prospective case series & 156 & 43 & $11.5 \ddagger$ & 1.6 & 4 \\
\hline \multicolumn{8}{|c|}{$\begin{array}{l}\text { OCEBM levels of evidence grades are as follows: } 1 \text { : systematic review of randomised trials; 2: randomised trial; 3: non-randomised controlled cohort/follow-up study; } 4 \text { : case series, case } \\
\text { control, or historical controlled study; } 5 \text { : mechanism-based reasoning. }\end{array}$} \\
\hline
\end{tabular}


demonstrated that BCVA gains are maintained up to 36 months after initiation of treatment. ${ }^{56-58} 61$

The 12-month, randomised RADIANCE trial $(\mathrm{N}=277)$ assessed the efficacy and safety of ranibizumab, administered under two different pro re nata $(\mathrm{PRN})$ schedules for myopic $\mathrm{CNV}$ compared with vPDT. ${ }^{52}$ Patients receiving PRN ranibizumab were treated according to two criteria: visual acuity stabilisation criteria (no treatment if no change in BCVA compared with two preceding monthly visits) or disease activity criteria (treatment if there is vision impairment attributable to intraretinal or subretinal fluid, or active leakage secondary to PM as assessed by OCT and/or FA).

RADIANCE showed that both PRN regimens of ranibizumab induced significantly greater gains in BCVA than vPDT (10.5 (visual acuity stabilisation criteria) and 10.6 (disease activity criteria) vs 2.2 letter change (vPDT) ) at month $3 .{ }^{52}$ By month 12 , the mean changes in BCVA were 13.8 (visual acuity stabilisation criteria) and 14.4 (disease activity criteria) letters for the two ranibizumab groups (with a median of 4.0 and 2.0 injections, respectively), compared with 9.3 letters for patients receiving vPDT who could be switched to ranibizumab from month 3 onwards (with a median of 2.0 injections between months 3 and 12). This indicates that patients who previously received vPDT could still gain vision when switched to ranibizumab. ${ }^{52}$ The results also suggested that either early treatment of myopic CNV with ranibizumab is important in preventing irreversible retinal damage, or that initial treatment with vPDT may have induced retinal damage, since patients in the vPDT arm switched to ranibizumab did not achieve the same visual gains as those treated initially with ranibizumab. Anatomical outcome improvements were also observed with ranibizumab and vPDT; the proportion of patients with $\mathrm{CNV}$ leakage and intraretinal oedema decreased substantially in all groups during the study. ${ }^{52}$

RADIANCE also revealed significant improvements in several quality of life parameters (ie, Visual Functioning Questionnaire 25 composite, general vision, mental health and dependency subscale scores) for patients treated with ranibizumab compared with vPDT, which were maintained through to 12 months (K Ohno-Matsui et al, ARVO Annual Meeting, Seattle, USA, 2013).

RADIANCE confirmed the results of the REPAIR trial $(\mathrm{N}=65)$, in which patients received one injection of ranibizumab followed by monthly monitoring and a PRN treatment regimen based on disease activity. ${ }^{53}$ In REPAIR, after 12 months of treatment, there was a mean BCVA change from baseline of 13.8 letters after receiving a median of 3.0 injections. ${ }^{53}$ Data from RADIANCE and REPAIR indicate that the safety profile of ranibizumab for treatment of myopic CNV is similar to that for AMD-CNV, retinal vein occlusion and diabetic macular oedema, ${ }^{52} 53$ with no new safety signals identified. Importantly, there were no retinal detachments, which is a concern in eyes with high myopia. 5253

\section{Bevacizumab}

Bevacizumab (Avastin) is not approved for intraocular use, and evidence on its safety and efficacy profile is limited. ${ }^{75} 76$ Increasing concerns regarding its safety have been raised, particularly with regards to the increased risk of cardiovascular events (eg, stroke) compared with ranibizumab, ${ }^{77} 78$ and the potential risk of infection after repackaging the drug for intravitreal use. ${ }^{78} 79$ Despite this, bevacizumab is used by many ophthalmologists, and several retrospective and prospective studies have shown increases in visual acuity of between 4 and 18 letters after 12 months (table 2). ${ }^{64-74} 80-82$ However, these studies are small and provide lower levels of evidence. Additionally, comparisons between trials should be made with caution, due to differences in study designs, patient populations etc.

Recent data have shown that the initial gains in visual acuity may not be maintained up to 5 years after treatment, and that this is associated with retinal thinning (V Sarao et al, ARVO Annual Meeting, Seattle, USA, 2013). This could indicate the development of chorioretinal atrophy, and like vPDT, it is not yet known whether this is related to treatment. However, a 4-year follow-up of 92 patients treated with bevacizumab $(n=68)$ or ranibizumab $(n=24)$ has shown good long-term outcomes, with changes in visual acuity of 9.4 letters at 12 months and 7.0 letters at 48 months (mean of 4.9 injections). ${ }^{83}$ Variability in treatment responses with anti-VEGF therapies in eyes with myopic $\mathrm{CNV}$ has been attributed to the size of the $\mathrm{CNV}$ lesion at baseline and the presence of single nucleotide polymorphisms in the VEGF gene. ${ }^{84} 85$ Further studies with larger numbers of patients are required to determine long-term outcomes with anti-VEGF therapies and prognostic factors for treatment responses.

As there have been no large prospective, randomised clinical trials with bevacizumab in myopic CNV, the optimal dosing frequency has not been established. In two studies directly comparing bevacizumab with ranibizumab in patients with myopic $\mathrm{CNV}$, there were similar improvements in BCVA, ${ }^{86} 87$ but the number of bevacizumab injections required was significantly higher in one study (4.7 vs $2.6, \mathrm{p}=0.0004) .{ }^{87}$ This may indicate an increased treatment burden with bevacizumab, but further studies are required.

\section{Aflibercept}

The efficacy and safety of aflibercept (Eylea) for myopic CNV was evaluated in the ongoing phase III, multicentre, randomised, sham-controlled, 12-month MYRROR study in Asian patients $\left(\mathrm{N}=121\right.$; NCT01249664). ${ }^{88}$ Patients received aflibercept according to a PRN schedule based on visual and anatomical criteria. ${ }^{89}$ Interim 6 -month results reported a 12.1-letter improvement in BCVA compared with a 2-letter loss in those receiving sham injection, ${ }^{89}$ and recent reports indicate sustained BCVA gains up to 12 months (K Ohno-Matsui et al, AAO Annual Meeting, New Orleans, USA, 2013).

\section{TREATMENT RECOMMENDATIONS FOR MYOPIC CNV}

Based on the evidence above, the following clinical management algorithm is proposed for diagnosis and treatment of myopic CNV (figure 3).

\section{Assessment and diagnosis}

Patients with myopia and reduced vision, central scotoma and/ or metamorphopsia should be referred to a retinal specialist. An early or urgent referral is recommended due to the potential for severe visual loss associated with the active stage of myopic $\mathrm{CNV}^{3}{ }^{26}{ }^{31}$ Myopic CNV may also regress spontaneously resulting in chorioretinal atrophy (figure 3), and the retinal specialist could lose the opportunity to treat the active CNV. Slit lamp biomicroscopy examination and imaging (FA and OCT) should be used to diagnose myopic CNV and differentiate it from other causes of CNV and other causes of visual loss associated with PM. ICGA may be required in selected cases.

\section{Initial treatment}

Once diagnosed, prompt treatment with a single intravitreal injection of anti-VEGF therapy is recommended due to the 
Figure 3 Treatment algorithm for myopic CNV.

*Ranibizumab is the only licensed anti-VEGF therapy for myopic CNV. Other anti-VEGFs (eg, bevacizumab and aflibercept) are not currently approved for myopic CNV. tInitiated with a single injection. $¥$ Monitoring for disease activity may include clinical examination, OCT or FA. If monitoring reveals signs of disease activity (reduced VA, blurred vision, metamorphopsia and/or lesion activity), further treatment is recommended.

CNV, choroidal neovascularisation; OCT, optical coherence tomography; $F A$, fluorescein angiography; VA, visual acuity; VEGF, vascular endothelial growth factor.

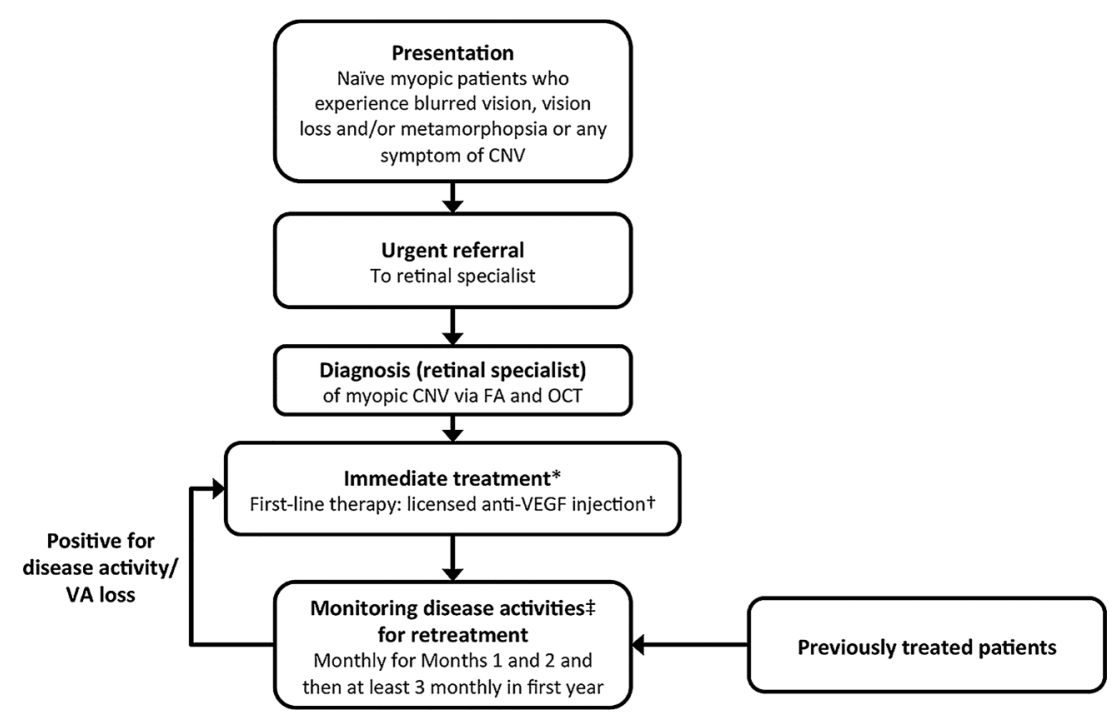

superior efficacy of anti-VEGFs over other treatment modalities. $^{52}$ Currently, ranibizumab is the only anti-VEGF therapy licensed for myopic CNV, although other agents are being evaluated. While some small studies in myopic CNV involved three initial injections followed by PRN dosing, ${ }^{56} 58$ the RADIANCE and REPAIR trials support the use of a single ranibizumab injection followed by PRN dosing. ${ }^{52} 54$ Patients previously treated with vPDT with recurrence of myopic CNV may also be switched to anti-VEGF therapy, as increases in BCVA were observed following a switch in treatment in the RADIANCE trial. $^{52}$ The results from a recent meta-analysis demonstrated that anti-VEGF therapy was more effective than vPDT in improving BCVA. ${ }^{90}$

Patients with extrafoveal CNV should also receive immediate treatment, as CNV-related chorioretinal atrophy could develop and affect central vision. In this instance, patients can also receive first-line treatment with anti-VEGF therapy, as the RADIANCE trial included patients with extrafoveal $\mathrm{CNV}^{52}$ However, vPDT could also be used when anti-VEGF therapy is not available or contraindicated.

\section{Follow-up}

After the initial anti-VEGF injection, patients should be monitored monthly for the first 2 months for disease activity, with clinical evaluation and appropriate imaging (OCT and/or FA). ${ }^{91}$ To assess the progression of myopic CNV, fundus autofluorescence may also be informative. ${ }^{4}$ Disease activity is defined as a drop in vision, new or persistent visual symptoms (eg, metamorphopsia) or signs of myopic CNV disease activity on FA/OCT (eg, intraretinal or subretinal fluid or active leakage). If disease activity is present, the patient should receive another anti-VEGF injection. This algorithm is supported by the efficacious outcomes of the REPAIR and RADIANCE studies, where patients were treated based on disease activity, defined as any leak on OCT/FA and/or a drop in BCVA associated with CNV activity. ${ }^{52-54}$ An alternative retreatment approach of treating based on visual acuity stability (also assessed in the RADIANCE trial) resulted in a similar visual acuity gain benefit relative to treating the morphology but required more treatments. ${ }^{52}$

If there is no disease activity after the initial injection and the two successive monthly visits, three-monthly visits may be considered for the first year. ${ }^{91}$ For some patients, quarterly monitoring may result in under treatment, so patients should be educated to re-present to the retinal specialist if they experience any decrease in vision or recurrence of metamorphopsia. More frequent monitoring and treatment could be established by the treating retinal specialist if there is evidence of disease activity. After 1 year, the monitoring frequency should be established by the retinal specialist in consultation with the patient, ${ }^{91}$ and the patient should be advised to return if they experience any drop in vision.

During monitoring, the treating retinal specialist should also check for additional pathologies, such as myopic traction maculopathy (foveoschisis), macular hole, retinal tears and rhegmatogenous detachments, which can also be causes of visual loss and require different treatments. ${ }^{92-95}$ This is particularly important for myopic traction maculopathy, as the acute shrinkage of $\mathrm{CNV}$ by anti-VEGF therapy can worsen a pre-existing retinoschisis. ${ }^{96}$ Patients with PM and myopic CNV should also be educated about the symptoms of these other retinal complications.

Of note, the number of anti-VEGF injections needed to treat myopic CNV is substantially lower than for other conditions such as AMD-CNV. The RADIANCE trial suggested patients received a median of 2.0 (mean 3.5) injections in the first 12 months under the PRN disease activity dosing regimen. ${ }^{52}$ Indeed, during months $6-12$ of this trial, $>60 \%$ of patients receiving ranibizumab did not require any injections. ${ }^{52}$

\section{CONCLUSION}

Treatment of myopic CNV with anti-VEGF agents allows promise of substantial visual acuity gain and quality of life. In particular, there is now a high level of evidence for the use of ranibizumab, the only anti-VEGF agent currently licensed, for treatment of myopic CNV, although others such as aflibercept are being evaluated in clinical trials. While the proposed treatment algorithm is based on the current knowledge and experience gained to date, further research will establish the best management strategy, dosing frequency and timing of injection and monitoring.

\footnotetext{
Author affiliations

${ }^{1}$ Singapore Eye Research Institute, Singapore National Eye Centre, National University of Singapore, Singapore, Singapore

${ }^{2}$ Department of Ophthalmology and Visual Science, Tokyo Medical and Dental University, Tokyo, Japan

${ }^{3}$ Faculté de Médecine de Poitiers, Department of Ophthalmology, Poitiers, France

${ }^{4}$ Department of Ophthalmology, University of Bonn, Bonn, Germany

${ }^{5}$ Department of Ophthalmology and Visual Sciences, Hong Kong Eye Hospital, The Chinese University of Hong Kong, People's Republic of China
} 
${ }^{6}$ Department of Ophthalmology, Seoul National University College of Medicine, Seoul, Korea

${ }^{7}$ Department of Ophthalmology, University of Udine, Piazzale S. Maria della Misericordia, Udine, Italy

${ }^{8}$ Department of Ophthalmology, Peking Union Medical College Hospital, Peking Union Medical College and Chinese Academy of Medical Sciences, Beijing, People's Republic of China

${ }^{9}$ NIHR Moorfields Biomedical Research Centre, Moorfields Eye Hospital, London, UK

Acknowledgements The authors thank Elizabeth Hutchinson (Fishawack Communications Ltd, UK) for medical writing and editorial assistance towards development of this manuscript, supported by Novartis Pharma AG.

Contributors At all stages the authors have had control over the content of this manuscript, for which they have given final approval and take full responsibility. TYW was the lead author and took overall responsibility for the scientific accuracy, flow and content of the manuscript. AT was responsible for the overall integrity of the manuscript and acts as the guarantor in accordance with ICJME requirements.

Funding Medical writing services and publication costs were supported by Novartis Pharma AG.

Competing interests TYW reports grants, personal fees, travel support and writing/reviewing fees from Novartis and Bayer, and has served as a consultant for Abbott, Allergan, Bayer, Genentech, Novartis, Roche, and Pfizer; KO-M has nothing to disclose; NL reports personal fees and non-financial support from Allergan, Bayer and Novartis, and grants from Théa; FGH reports advisory board remuneration from Acucela, Alcon, Bayer, Genentech, Heidelberg Engineering, Merz, Novartis and Roche; TYL reports advisory board and consultancy remuneration from Allergan, Bayer, Novartis, and lecture fees from Alcon, Allergan, Bausch \& Lomb, Bayer Healthcare, Heidelberg Engineering and Novartis; HGY reports grants from Allergan, Bayer and Novartis; PL is a consultant for Alcon, Allergan, Bausch \& Lomb, Bayer, Novartis, Roche and Teva; YC reports advisory board remuneration from Novartis; AT reports advisory board remuneration from Alcon, Allergan, Bayer, Novartis, Roche, Genentech, Heidelberg Engineering, Pfizer and ThromboGenics.

Provenance and peer review Commissioned; externally peer reviewed.

Open Access This is an Open Access article distributed in accordance with the Creative Commons Attribution Non Commercial (CC BY-NC 3.0) license, which permits others to distribute, remix, adapt, build upon this work non-commercially, and license their derivative works on different terms, provided the original work is properly cited and the use is non-commercial. See: http://creativecommons.org/ licenses/by-nc/3.0/

\section{REFERENCES}

1 Avila MP, Weiter JJ, Jalkh $\mathrm{AE}$, et al. Natural history of choroidal neovascularization in degenerative myopia. Ophthalmology 1984;91:1573-81.

2 Fried M, Siebert A, Meyer-Schwickerath G, et al. Natural history of Fuchs' spot: a long-term follow-up study. Doc Ophthal Proc Series 1981;28:215-21.

3 Hampton GR, Kohen D, Bird AC. Visual prognosis of disciform degeneration in myopia. Ophthalmology 1983;90:923-6.

4 Neelam K, Cheung CM, Ohno-Matsui K, et al. Choroidal neovascularization in pathological myopia. Prog Retin Eye Res 2012;31:495-525.

5 Leveziel N, Yu Y, Reynolds R, et al. Genetic factors for choroidal neovascularization associated with high myopia. Invest Ophthalmol Vis Sci 2012;53:5004-9.

6 Ikuno Y, Jo Y, Hamasaki T, et al. Ocular risk factors for choroidal neovascularization in pathologic myopia. Invest Ophthalmol Vis Sci 2010:51:3721-5.

7 Seko Y, Fujikura H, Pang J, et al. Induction of vascular endothelial growth factor after application of mechanical stress to retinal pigment epithelium of the rat in vitro. Invest Ophthalmol Vis Sci 1999;40:3287-91.

8 Ohno-Matsui K, Yoshida T, Futagami S, et al. Patchy atrophy and lacquer cracks predispose to the development of choroidal neovascularisation in pathological myopia. Br J Ophthalmol 2003;87:570-3.

9 Hayashi K, Ohno-Matsui K, Shimada N, et al. Long-term pattern of progression of myopic maculopathy: a natural history study. Ophthalmology 2010;117:1595-611.

10 Fredrick DR. Myopia. BMJ 2002;324:1195-9.

11 Akagi-Kurashige Y, Kumagai K, Yamashiro K, et al. Vascular endothelial growth factor gene polymorphisms and choroidal neovascularization in highly myopic eyes. Invest Ophthalmol Vis Sci 2012;53:2349-53.

12 Miyake M, Yamashiro K, Nakanishi $\mathrm{H}$, et al. Evaluation of pigment epithelium-derived factor and complement factor I polymorphisms as a cause of choroidal neovascularization in highly myopic eyes. Invest Ophthalmol Vis Sci 2013:54:4208-12.

13 Wakabayashi T, Ikuno Y. Choroidal filling delay in choroidal neovascularisation due to pathological myopia. Br J Ophthalmol 2010;94:611-15.

14 Steidl SM, Pruett RC. Macular complications associated with posterior staphyloma. Am J Ophthalmol 1997:123:181-7.

15 Chan WM, Ohji M, Lai TY, et al. Choroidal neovascularisation in pathological myopia: an update in management. Br J Ophthalmol 2005;89:1522-8.
16 Miller DG, Singerman LJ. Natural history of choroidal neovascularization in high myopia. Curr Opin Ophthalmol 2001;12:222-4.

17 Soubrane G. Choroidal neovascularization in pathologic myopia: recent developments in diagnosis and treatment. Surv Ophthalmol 2008:53:121-38.

18 Verteporfin in Photodynamic Therapy Study Group. Photodynamic therapy of subfoveal choroidal neovascularization in pathologic myopia with verteporfin. 1-year results of a randomized clinical trial—VIP report no. 1. Ophthalmology 2001:108:841-52.

19 Channa R, Ibrahim M, Sepah Y, et al. Characterization of macular lesions in punctate inner choroidopathy with spectral domain optical coherence tomography. J Ophthalmic Inflamm Infect 2012;2:113-20.

20 Vance SK, Khan S, Klancnik JM, et al. Characteristic spectral-domain optical coherence tomography findings of multifocal choroiditis. Retina 2011;31:717-23.

21 Watzke RC, Packer AJ, Folk JC, et al. Punctate inner choroidopathy. Am J Ophthalmol 1984:98:572-84.

22 Silva R. Myopic maculopathy: a review. Ophthalmologica 2012;228:197-213.

23 Wong TY, Ferreira A, Hughes $R$, et al. Epidemiology and disease burden of pathologic myopia and myopic choroidal neovascularization: an evidence-based systematic review. Am J Ophthalmol 2014;157:9-25 e12.

24 Leveziel N, Caillaux V, Bastuji-Garin S, et al. Angiographic and optical coherence tomography characteristics of recent myopic choroidal neovascularization. Am J Ophthalmol 2013;155:913-19.

25 Jonas JB, Jonas SB, Jonas RA, et al. Parapapillary atrophy: histological gamma zone and delta zone. PLoS One 2012:7:e47237.

26 Yoshida T, Ohno-Matsui K, Yasuzumi K, et al. Myopic choroidal neovascularization: a 10-year follow-up. Ophthalmology 2003;110:1297-305.

27 Kojima A, Ohno-Matsui K, Teramukai S, et al. Estimation of visual outcome without treatment in patients with subfoveal choroidal neovascularization in pathologic myopia. Graefes Arch Clin Exp Ophthalmol 2006;244:1474-9.

28 Yoshida T, Ohno-Matsui K, Ohtake Y, et al. Long-term visual prognosis of choroidal neovascularization in high myopia: a comparison between age groups. Ophthalmology 2002:109:712-19.

29 Hayashi K, Ohno-Matsui K, Yoshida T, et al. Characteristics of patients with a favorable natural course of myopic choroidal neovascularization. Graefes Arch Clin Exp Ophthalmol 2005;243:13-19.

30 Hotchkiss ML, Fine SL. Pathologic myopia and choroidal neovascularization. Am J Ophthalmol 1981;91:177-83.

31 Tabandeh H, Flynn HW Jr, Scott IU, et al. Visual acuity outcomes of patients 50 years of age and older with high myopia and untreated choroidal neovascularization. Ophthalmology 1999;106:2063-7.

32 Ruiz-Moreno JM, Montero JA. Long-term visual acuity after argon green laser photocoagulation of juxtafoveal choroidal neovascularization in highly myopic eyes. Eur J Ophthalmol 2002;12:117-22.

33 Tano Y. Pathologic myopia: where are we now? Am J Ophthalmol 2002;134:645-60.

34 Virgili G, Menchini F. Laser photocoagulation for choroidal neovascularisation in pathologic myopia. Cochrane Database Syst Rev 2005:CD004765.

35 Secretan M, Kuhn D, Soubrane G, et al. Long-term visual outcome of choroidal neovascularization in pathologic myopia: natural history and laser treatment. Eur J Ophthalmol 1997;7:307-16.

36 Altan T, Acar N, Kapran Z, et al. Outcome of photodynamic therapy in choroidal neovascularization due to pathologic myopia and related factors. Int Ophthalmol 2012:32:119-25

37 Chan WM, Lai TY, Wong AL, et al. Combined photodynamic therapy and intravitrea triamcinolone injection for the treatment of choroidal neovascularisation secondary to pathological myopia: a pilot study. Br J Ophthalmol 2007;91:174-9.

38 Chen YS, Lin JY, Tseng SY, et al. Photodynamic therapy for Taiwanese patients with pathologic myopia: a 2-year follow-up. Retina 2007;27:839-45.

39 Costa RA, Williams GA. Twofold illumination photodynamic therapy scheme for subfoveal choroidal neovascularization in pathologic myopia: results from a randomized pilot study. Retina 2006:26:757-64.

40 Hayashi K, Ohno-Matsui K, Shimada N, et al. Long-term results of photodynamic therapy for choroidal neovascularization in Japanese patients with pathologic myopia. Am J Ophthalmol 2011;151:137-47 e1.

41 Hayashi K, Ohno-Matsui K, Teramukai S, et al. Photodynamic therapy with verteporfin for choroidal neovascularization of pathologic myopia in Japanese patients: comparison with nontreated controls. Am J Ophthalmol 2008;145:518-26.

42 Krebs I, Binder S, Stolba U, et al. Choroidal neovascularization in pathologic myopia: three-year results after photodynamic therapy. Am J Ophthalmol 2005; 140:416-25.

43 Lam DS, Chan WM, Liu DT, et al. Photodynamic therapy with verteporfin for subfoveal choroidal neovascularisation of pathologic myopia in Chinese eyes: a prospective series of 1 and 2 year follow up. Br J Ophthalmol 2004;88:1315-19.

44 Montero JA, Ruiz-Moreno JM. Verteporfin photodynamic therapy in highly myopic subfoveal choroidal neovascularisation. Br J Ophthalmol 2003;87:173-6.

45 Pece A, Isola V, Vadala M, et al. Photodynamic therapy with verteporfin for subfoveal choroidal neovascularization secondary to pathologic myopia: long-term study. Retina 2006;26:746-51. 
46 Pece A, Milani P, Isola V, et al. A long-term study of photodynamic therapy with verteporfin for choroidal neovascularization at the edge of chorioretinal atrophy in pathologic myopia. Ophthalmologica 2011;225:161-8.

47 Pece A, Vadala M, Isola V, et al. Photodynamic therapy with verteporfin for juxtafoveal choroidal neovascularization in pathologic myopia: a long-term follow-up study. Am J Ophthalmol 2007;143:449-54.

48 Coutinho AM, Silva RM, Nunes SG, et al. Photodynamic therapy in highly myopic eyes with choroidal neovascularization: 5 years of follow-up. Retina 2011;31:1089-94.

49 Giansanti F, Virgili G, Donati MC, et al. Long-term results of photodynamic therapy for subfoveal choroidal neovascularization with pathologic myopia. Retina 2012:32:1547-52.

50 Schnurrbusch UE, Jochmann C, Wiedemann P, et al. Quantitative assessment of the long-term effect of photodynamic therapy in patients with pathologic myopia. Graefes Arch Clin Exp Ophthalmol 2005;243:829-33.

51 Blinder KJ, Blumenkranz MS, Bressler NM, et al. Verteporfin therapy of subfoveal choroidal neovascularization in pathologic myopia: 2-year results of a randomized clinical trial—VIP report no. 3. Ophthalmology 2003;110:667-73.

52 Wolf S, Balciuniene VJ, Laganovska G, et al. RADIANCE: a randomized controlled study of ranibizumab in patients with choroidal neovascularization secondary to pathologic myopia. Ophthalmology 2014;121:682-92.

53 Tufail A, Narendran N, Patel PJ, et al. Ranibizumab in myopic choroidal neovascularization: the 12-month results from the REPAIR study. Ophthalmology 2013;120:1944-5.

54 Tufail A, Patel PJ, Sivaprasad S, et al. Ranibizumab for the treatment of choroidal neovascularisation secondary to pathological myopia: interim analysis of the REPAIR study. Eye (Lond) 2013;27:709-15.

55 OCEBM Levels of Evidence Working Group. The Oxford Levels of Evidence 2. Oxford Centre for Evidence-Based Medicine. 2011. http://www.cebm.net/index.aspx? $0=5653$ (accessed 13 Nov 2013)

56 Calvo-Gonzalez C, Reche-Frutos J, Donate J, et al. Intravitreal ranibizumab for myopic choroidal neovascularization: factors predictive of visual outcome and need for retreatment. Am J Ophthalmol 2011;151:529-34.

57 Franqueira N, Cachulo ML, Pires I, et al. Long-term follow-up of myopic choroidal neovascularization treated with ranibizumab. Ophthalmologica 2012;227:39-44.

58 Lai TY, Luk FO, Lee GK, et al. Long-term outcome of intravitreal anti-vascular endothelial growth factor therapy with bevacizumab or ranibizumab as primary treatment for subfoveal myopic choroidal neovascularization. Eye (Lond) 2012;26:1004-11.

59 Monés JM, Amselem L, Serrano A, et al. Intravitreal ranibizumab for choroidal neovascularization secondary to pathologic myopia: 12-month results. Eye (Lond) 2009;23:1275-80, quiz 81.

60 Silva RM, Ruiz-Moreno JM, Rosa P, et al. Intravitreal ranibizumab for myopic choroidal neovascularization: 12-month results. Retina 2010;30:407-12.

61 Vadala M, Pece A, Cipolla $S$, et al. Is ranibizumab effective in stopping the loss of vision for choroidal neovascularisation in pathologic myopia? A long-term follow-up study. Br J Ophthalmol 2011;95:657-61.

62 Lai TY, Chan WM, Liu DT, et al. Intravitreal ranibizumab for the primary treatment of choroidal neovascularization secondary to pathologic myopia. Retina 2009:29:750-6.

63 Yoon JU, Byun YJ, Koh HJ. Intravitreal anti-VEGF versus photodynamic therapy with verteporfin for treatment of myopic choroidal neovascularization. Retina 2010;30:418-24

64 Ikuno Y, Sayanagi K, Soga K, et al. Intravitreal bevacizumab for choroidal neovascularization attributable to pathological myopia: one-year results. Am J Ophthalmol 2009;147:94-100 e1.

65 Chan WM, Lai TY, Liu DT, et al. Intravitreal bevacizumab (Avastin) for myopic choroidal neovascularisation: 1-year results of a prospective pilot study. $\mathrm{Br} J$ Ophthalmol 2009;93:150-4.

66 Gharbiya M, Allievi F, Mazzeo L, et al. Intravitreal bevacizumab treatment for choroidal neovascularization in pathologic myopia: 12-month results. Am J Ophthalmol 2009;147:84-93 e1.

67 Ruiz-Moreno JM, Montero JA, Amat-Peral P. Myopic choroidal neovascularization treated by intravitreal bevacizumab: comparison of two different initial doses. Graefes Arch Clin Exp Ophthalmol 2011;249:595-9.

68 Ruiz-Moreno JM, Montero JA, Arias L, et al. Twelve-month outcome after one intravitreal injection of bevacizumab to treat myopic choroidal neovascularization. Retina 2010;30:1609-15.

69 Ruiz-Moreno JM, Lopez-Galvez MI, Donate J, et al. Myopic choroidal neovascularization. Ophthalmology 2011;118:2521-3.

70 Ruiz-Moreno JM, Lopez-Galvez MI, Montero Moreno JA, et al. Intravitreal bevacizumab in myopic neovascular membranes: 24-month results. Ophthalmology 2013;120:1510-11 e1.

71 lacono P, Parodi MB, Papayannis A, et al. Intravitreal bevacizumab therapy on an as-per-needed basis in subfoveal choroidal neovascularization secondary to pathological myopia: 2-year outcomes of a prospective case series. Retina 2011;31:1841-7

72 Gharbiya M, Cruciani F, Parisi F, et al. Long-term results of intravitreal bevacizumab for choroidal neovascularisation in pathological myopia. Br J Ophthalmol 2012;96:1068-72.

73 Hayashi K, Shimada N, Moriyama M, et al. Two-year outcomes of intravitreal bevacizumab for choroidal neovascularization in Japanese patients with pathologic myopia. Retina 2012:32:687-95.

74 Hayashi K, Ohno-Matsui K, Teramukai S, et al. Comparison of visual outcome and regression pattern of myopic choroidal neovascularization after intravitreal bevacizumab or after photodynamic therapy. Am J Ophthalmol 2009;148: 396-408.

75 Chakravarthy U, Harding SP, Rogers CA, et al. Alternative treatments to inhibit VEGF in age-related choroidal neovascularisation: 2-year findings of the IVAN randomised controlled trial. Lancet 2013;382:1258-67.

76 Martin DF, Maguire MG, Fine SL, et al. Ranibizumab and bevacizumab for treatment of neovascular age-related macular degeneration: two-year results. Ophthalmology 2012;119:1388-98.

77 Curtis LH, Hammill BG, Schulman KA, et al. Risks of mortality, myocardial infarction, bleeding, and stroke associated with therapies for age-related macular degeneration. Arch Ophthalmol 2010;128:1273-9.

78 Cruess AF, Giacomantonio N. Cardiac issues of noncardiac drugs: the rising story of Avastin in age-related macular degeneration. Ophthalmologica 2014;231:75-9.

79 US Food and Drug Administration. Potential use of Avastin in the treatment of wet age-related macular degeneration. 2011. http://www.fda.gov/Drugs/DrugSafety/ ucm270296.htm (accessed $11 \mathrm{Jul}$ 2013).

80 Nakanishi H, Tsujikawa A, Yodoi Y, et al. Prognostic factors for visual outcomes 2-years after intravitreal bevacizumab for myopic choroidal neovascularization. Eye (Lond) 2011:25:375-81.

81 Parodi MB, lacono P, Papayannis A, et al. Laser photocoagulation, photodynamic therapy, and intravitreal bevacizumab for the treatment of juxtafoveal choroidal neovascularization secondary to pathologic myopia. Arch Ophthalmol 2010;128:437-42.

82 Yodoi Y, Tsujikawa A, Nakanishi $H$, et al. Central retinal sensitivity after intravitreal injection of bevacizumab for myopic choroidal neovascularization. Am J Ophthalmol 2009;147:816-24, 24 e1.

83 Ruiz-Moreno JM, Arias L, Montero JA, et al. Intravitreal anti-VEGF therapy for choroidal neovascularisation secondary to pathological myopia: 4-year outcome. Br J Ophthalmol 2013;97:1447-50.

84 Yang HS, Kim JG, Kim JT, et al. Prognostic factors of eyes with naïve subfoveal myopic choroidal neovascularization after intravitreal bevacizumab. Am J Ophthalmol 2013;156:1201-10 e2.

85 Miyake M, Yamashiro K, Akagi-Kurashige Y, et al. Vascular endothelial growth factor gene and the response to anti-vascular endothelial growth factor treatment for choroidal neovascularization in high myopia. Ophthalmology 2014;121: 225-33.

86 Gharbiya M, Giustolisi R, Allievi F, et al. Choroidal neovascularization in pathologic myopia: intravitreal ranibizumab versus bevacizumab-a randomized controlled trial. Am J Ophthalmol 2010;149:458-64 e1.

87 lacono $P$, Parodi MB, Papayannis $A$, et al. Intravitreal ranibizumab versus bevacizumab for treatment of myopic choroidal neovascularization. Retina 2012:32:1539-46.

88 ClinicalTrials.gov. VEGF trap-eye in choroidal neovascularization secondary to pathologic myopia (mCNV) (MYRROR). 2012. http://clinicaltrials.gov/ct2/show/ NCT01249664?term=aflibercept+AND+myopia\&rank=1 (accessed 1 Jul 2013)

89 Bayer HealthCare. Positive phase 3 results for VEGF Trap-Eye (intravitreal aflibercept) in myopic choroidal neovascularization (mCNV). 2013. http://press. healthcare.bayer. com/en/press/auth/news-details-page.php/15070/2013-0317 (accessed 25 Jul 2013).

90 Wang E, Chen Y. Intravitreal anti-vascular endothelial growth factor for choroidal neovascularization secondary to pathologic myopia: systematic review and meta-analysis. Retina 2013;33:1375-92.

91 Novartis. Lucentis summary of product characteristics. 2012. http://www.ema europa.eu/docs/en_GB/document_library/EPAR_-_Product_Information/human/ 000715/WC500043546.pdf (accessed 13 Nov 2013).

92 Akiba J. Prevalence of posterior vitreous detachment in high myopia. Ophthalmology 1993;100:1384-8.

93 Kobayashi H, Kobayashi K, Okinami S. Macular hole and myopic refraction. Br J Ophthalmol 2002;86:1269-73.

94 Lewis $\mathrm{H}$. Peripheral retinal degenerations and the risk of retinal detachment. Am J Ophthalmol 2003;136:155-60.

95 Tang J, Rivers MB, Moshfeghi AA, et al. Pathology of macular foveoschisis associated with degenerative myopia. J Ophthalmol 2010;2010:175613.

96 Shimada N, Ohno-Matsui K, Hayashi K, et al. Macular detachment after successful intravitreal bevacizumab for myopic choroidal neovascularization. Jpn J Ophthalmol 2011;55:378-82 